\section{ESPORTE PARA O DESENVOLVIMENTO E A PAZ: LEITURAS ACADÊMICAS EM DIÁLOGO COM OS USOS DO ESPORTE PARA A PACIFICAÇÃO NO RIO DE JANEIRO}

\author{
SPORTS FOR DEVELOPMENT AND PEACE: ACADEMIC READINGS ON THE \\ USE OF SPORTS FOR PACIFICATION IN RIO DE JANEIRO
}

DEPORTE PARA EL DESARROLLO Y LA PAZ: LECTURAS ACADÉMICAS EN DIÁLOGO CON LOS USOS DEL DEPORTE PARA LA PACIFICACIÓN EN EL RIO DE JANEIRO

\author{
Nadyne Venturini Trindade*, Bárbara Schausteck de Almeida*, \\ Wanderley Marchi Júnior*
}

Palavras chave:

Esportes.

Projetos de

Investimento Social.

Desenvolvimento da comunidade.
Resumo: Este artigo discute o uso do esporte para a promoção da paz e os principais aspectos analisados no contexto internacional, traçando correspondências e alteridades com as ações promovidas nas áreas de pacificação no Rio de Janeiro. A partir da revisão da literatura com base em procedimentos da revisão sistemática, observou-se que a falta de sensibilidade cultural e de consideração dos processos de exclusão social por parte de seus idealizadores resultam na crescente militarização do espaço das comunidades, 0 que impõe limites à sustentabilidade desses projetos esportivos a longo prazo.
Keywords:

Sports.

Social Investment

Projects.

Development.
Community

Abstract: This article discusses the use of sports to promote peace and the main aspects analyzed in the international context, indicating similarities to and differences from the actions promoted in the so-called "pacification" in areas in Rio de Janeiro. A literature review based on systematic review procedures found that the lack of cultural sensitivity and consideration for social exclusion processes by its creators results in increasing militarization of space in those communities, which restricts the long-term sustainability of those sports projects.

Palabras clave:

Deportes

Proyectos de Inversión Social. Desarrollo de la Comunidad.
Resumen: En este artículo se discute el uso del deporte para promover la paz a partir de los principales aspectos analizados en el contexto internacional, indicando las similitudes y las alteridades con las acciones promovidas en las zonas de pacificación de Río de Janeiro. A partir de la revisión de la literatura basada en los procedimientos de revisión sistemática, se observó que la falta de sensibilidad cultural y consideración de los procesos de exclusión social por sus creadores dan como resultado el aumento de la militarización del espacio de las comunidades, que impone límites en la sostenibilidad de estos proyectos deportivos en el largo plazo.
*Universidade Federal do Paraná. Curitiba, PR, Brasil. E-mail: nadynetrindade@gmail.com; barbaracwb@gmail.com; wmarchijr@gmail.com

Recebido em: 09-08-2016 Aprovado em: 21-09-2017

DOI: http://dx.doi.org/10.22456/1982-8918.66829 (c) (1) 은 Licence 


\section{INTRODUÇÃOO}

A relação entre esporte e política social pode parecer ser algo relativamente novo; no entanto, a ideia de que o esporte pode ser usado com objetivos sociais mais amplos é central para a história do esporte moderno (MANGAN, 2000). É nas últimas duas décadas que 0 esporte aparece de modo mais recorrente em políticas sociais que visam promover a inclusão social, a coesão das comunidades, o diálogo intercultural e a cultura de paz (KIDD, 2008). Apesar desse movimento ser contestado por diferentes correntes teóricas e ideológicas, 0 discurso sobre o valor instrumental do esporte mostra-se relevante, tanto para a formulação de ações e políticas públicas e privadas, quanto nas pesquisas acadêmicas. As Agências das Nações Unidas para o Esporte para Desenvolvimento e Paz (EDP) e o Comitê Olímpico Internacional (COI) têm atuado como as principais instituições proponentes dessa visão, advogando o papel fundamental do esporte e do movimento olímpico na concretização dos Objetivos de Desenvolvimento Sustentável por meio do uso de parcerias globais tidas como inovadoras (COMITÊ OLÍMPICO INTERNACIONAL, 2015b; ORGANIZAÇÃO DAS NAÇÕES UNIDAS, 2003; PROGRAMA DAS NAÇÕES UNIDAS PARA O DESENVOLVIMENTO, 2016) 1 .

Não é recente a crítica que se faz às políticas sociais enquanto forma de controle social, na qual o sistema de bem-estar (welfare) torna-se mais ocupado com o controle de pessoas do que com satisfação das suas necessidades ou com o respeito aos seus direitos de cidadania (BLAKEMORE; GRIGGS, 2007). As interpretações neomarxistas e pós-modernas sobre 0 tema defendem que 0 controle social exercido por essas iniciativas pode ser diretamente coercitivo, de tal forma que a autonomia ou a liberdade de um indivíduo é deliberadamente $\mathrm{e}$, obviamente, suprimida, ou sutilmente opressiva, incentivando as pessoas a se encaixarem em papéis sociais aceitos ou a suprimirem a individualidade de modo menos evidente (NYGÅRD; GATES, 2013).

O trabalho de Spaaij (2009) mostra que as políticas esportivas destinadas à promoção da inclusão social de crianças e adolescentes desfavorecidos tendem a operar num contexto político-ideológico mais amplo, que se concentra na geração da ordem em bairros urbanos pobres e normaliza o comportamento daqueles que residem neles, sobretudo os jovens "em risco" e as minorias étnicas. Pode-se debater que, no contexto mais amplo de preocupação política sobre a coesão social, imigração e crime, servir o público-alvo não é o objetivo final de tais programas esportivos. Em última análise, eles são vistos como um meio através do qual as agências governamentais e seus parceiros buscam civilizar e regular grupos sociais específicos, a fim de normatizar seus comportamentos, fazê-los cumprir com responsabilidades sociais e integrá-los à sociedade. Assim, intervenções com foco no esporte também tendem a servir como uma forma de controle social e de regulação (GAWRYSZEWSKI, 2013; JESUS, 2011; SPAAIJ, 2009).

No contexto brasileiro, os projetos sociais esportivos em áreas carentes são ofertados desde os anos de 1980, passando por um período de franca expansão na última década e despertando 0 interesse de pesquisadores de diversas áreas, incluindo a Educação Física

1 Os Objetivos de Desenvolvimento Sustentável das Nações Unidas são as metas que visam atender as necessidades humanas fundamentais, como a erradicação da fome e da pobreza extrema, acesso à educação primária universal, redução da mortalidade infantil e infecção pelo vírus HIV e a promoção da igualdade entre os sexos. No âmbito esportivo, um esforço maior deve ser dedicado à construção da cultura de paz e resolução de conflitos, uma vez que a pacificação é considerada uma precondição para a implementação dessas metas e de outras iniciativas de desenvolvimento (SPORT FOR DEVELOPMENT AND PEACE INTERNATIONAL WORKING GROUP, 2008). 
(KRAVCHYCHYN; OLIVEIRA, 2015). Dentre as diferentes propostas de atuação desses projetos, aquelas que usam o esporte como meio de promover a pacificação são vistas por alguns pesquisadores como o "calcanhar de Aquiles" do setor de EDP (COALTER, 2007; KIDD, 2008; SUGDEN; HAASNER, 2008). Mesmo no campo de estudos sobre pacificação, a noção de paz é tida como um conceito evasivo e problemático, pois abarca uma variedade de significados que vão desde a ausência de guerra a um estado de equilíbrio e tranquilidade (GALTUNG, 1996).

No que se refere ao delineamento do conceito de violência, é recorrente a adoção da definição cunhada pela Organização Mundial da Saúde (WHO, 1996, p. 2, tradução nossa), na qual a violência é descrita como "[...] o uso intencional de força física ou poder, em ameaça ou na prática, contra si próprio, outra pessoa ou contra um grupo ou comunidade que resulte ou possa resultar em sofrimento, morte, dano psicológico, desenvolvimento prejudicado ou privação". Todavia, o trabalho de Aisenberg et al. (2011) aponta que as diferentes compreensões que se construíram no seio de áreas acadêmicas distintas impõem desafios práticos para o estudo, a prevenção e o combate da violência. Para os autores a falta do diálogo interdisciplinar inviabiliza uma definição uniforme, resultando em abordagens fragmentadas nas pesquisas e nas intervenções destinadas a reduzir o comportamento violento e o crime. Há, também, segundo esses autores, uma dificuldade operacional de trabalhar com a interação e a interseção dos fatores individuais com os aspectos estruturais e contextuais, tais como a pobreza, a cultura, o racismo, o sexismo e outros sistemas de estratificação.

No Brasil, o levantamento mais sistemático sobre a violência tem sido desenvolvido no Mapa da Violência, por meio de indicadores ligados às taxas de homicídios e outros aspectos demográficos, como o sexo e a idade das vítimas. No entanto, como Zdun (2011) problematiza, mesmo nas grandes capitais brasileiras, como o Rio de Janeiro, as diferentes esferas públicas não são capazes de registrar e acompanhar os números de homicídios de modo efetivo. A despeito da falta de fidedignidade nos dados disponíveis, Cerqueira (2010) apontou em sua tese sete indicadores nacionais de mudanças socioeconômicas entre $1980 \mathrm{e}$ 2007 e os relacionou com as tendências de homicídio através desses anos. Os sete indicadores foram: renda nacional, níveis de desigualdade (índice de Gini), proporção de jovens do sexo masculino (15-24 anos) na população, disponibilidade de armas de fogo, uso de drogas ilegais, número de policiais e taxas de encarceramento. As variações nesses indicadores apontaram para alterações nas taxas de homicídio no país durante o período. Contudo, esses indicadores têm pouca consonância com as ações preventivas primárias que os projetos sociais esportivos destinados à crianças e adolescentes desenvolvem.

Assim, a problemática que permeia o setor EDP, e em particular os projetos que objetivam promover a pacificação, tem início na dificuldade de se operar com os conceitos que fazem parte da narrativa sobre o potencial social dessas iniciativas e, consequentemente, na seleção dos indicadores que poderiam apontar para a efetividade desses projetos e servir como critérios orientadores para essas ações.

Apesar disso, a difusão de projetos, tanto em áreas urbanas brasileiras afetadas pelo alto índice de violência quanto em comunidades em processo de reconciliação pós-conflito pelo mundo, sugere que a opinião dos proponentes dessas iniciativas é positiva quanto ao potencial do esporte como meio de promoção da cultura de paz, da mediação da diferença e da redução da criminalidade. 
Para Lindsey e Grattan (2012), o setor de EDP é mais difuso do que os críticos ao caráter neocolonialista dessas iniciativas sugerem, uma vez que nem todos os projetos contam com ajuda internacional e algumas iniciativas locais não se encaixam nas críticas que o movimento recebe. Para esses autores, a área carece de estudos que tragam diferentes perspectivas geopolíticas dentro de análises comparativas. É nesta direção que reconhecemos a possibilidade de investigar os paralelos entre o EDP e os projetos esportivos em comunidades carentes no Brasil.

O setor de EDP é constituído por estratégias de intervenção que, além de fomentar o direito à participação em atividades de esporte e lazer, atuam em cinco frentes de ação específicas: 1) promoção da igualdade de gênero; 2) desenvolvimento de crianças e adolescentes; 3) inclusão de pessoas com deficiência; 4) educação em saúde; e 5) construção da cultura de paz e resolução de conflitos (SPORT FOR DEVELOPMENT AND PEACE INTERNATIONAL WORKING GROUP, 2008). Diversos pesquisadores têm estudado os projetos sociais esportivos dentro do setor do EDP partindo do entendimento de que estas iniciativas locais fazem parte de um movimento global (DONNELLY et al., 2011; GIULIANOTTI, 2011; KIDD, 2008; SPAAIJ, 2009). Desta forma, defende-se a necessidade de se produzir trabalhos analíticos (GIULIANOTTI, 2011) que construam e compartilhem um corpo mais robusto de conhecimentos, proporcionando assim uma maior compreensão do papel do esporte dentro desse movimento (COALTER, 2007; SUGDEN; HAASNER, 2009).

Ao longo deste artigo fazemos uma análise do conhecimento já elaborado sobre as ações de promoção da paz por meio do esporte partindo da seguinte questão norteadora: a partir das análises sobre o esporte para a paz na literatura, quais são os paralelos que podem ser traçados com o uso do esporte nas favelas pacificadas do Rio de Janeiro? Para isso, nos concentraremos nos processos subjacentes a esses esforços, destacando os pontos críticos e as recomendações apontadas na literatura. Iniciaremos com apontamentos sobre os usos do esporte para a promoção da paz e os principais aspectos analisados sobre essas ações no contexto internacional. A partir dessas contribuições, serão traçadas as correspondências e alteridades com o que vem sendo produzido sobre as iniciativas brasileiras.

\section{PROCEDIMENTOS METODOLÓGICOS}

Para produzir um mapeamento do conhecimento já elaborado sobre o tema, foi realizada uma revisão da literatura com base em procedimentos da revisão sistemática. A etapa preliminar consistiu na busca nas bases eletrônicas SciELO (www.scielo.org), Scopus (www. scopus.com), Lilacs (www.lilacs.bvsalud.org), e Periódicos Capes (www.periodicos.capes. gov.br), com os seguintes descritores: "projeto social", "programa social", "projeto esportivo", "projeto sócio-esportivo", "projeto socioesportivo" e "esporte comunitário" combinados com os termos "esporte", "esportivo", "violência", "pacificação", "paz", "criminalidade juvenil", "drogas" e "UPP". Para as buscas em inglês foram utilizados os seguintes termos: "sport for development and peace", "sport-for-development', "sport-based program", "community program", "grassroof', combinados com os termos "sport", "violence", "peace", "peacemaking", "peace building" e "post conflict".

A busca foi realizada entre os meses de janeiro e julho de 2016 e incluiu os artigos publicados até 0 ano de 2016. Foi levantado um total de 114 artigos, dos quais 68 foram excluídos 
após a leitura dos títulos e dos resumos. A seleção dos 46 artigos para a leitura na íntegra levou em consideração a validade. Nesta etapa, 13 artigos foram excluídos por não estarem relacionados com a questão norteadora. A amostra final foi composta por 33 publicações (19 em inglês e 14 em português) com um intervalo temporal entre os anos de 1985 e 2016. Além dos artigos, foram utilizados ainda livros em inglês, conforme disponibilidade e acesso, fontes oficiais de instituições relacionadas, como da Organização das Nações Unidas (ONU) e do Governo do Estado do Rio de Janeiro, com o propósito de apresentar e contextualizar suas ações e posicionamentos.

\section{RESULTADOS E DISCUSSÃO}

\subsection{O panorama das propostas}

O uso do esporte para a reconciliação, a promoção da cultura de paz e a prevenção da violência acontece tanto nos chamados "países em desenvolvimento" quanto nos "países desenvolvidos". Apesar das especificidades e divergências entre o que é feito em cada país, os estudos sobre essas estratégias nacionais de pacificação e resolução de conflitos por meio do esporte são relativamente escassos e apenas um número reduzido dialoga com as teorias sobre a pacificação (CARDENAS, 2013; GÜLDENPFENNIG, 1985; SUGDEN; HAASNER, 2009). Sugden e Haasner (2009) apontam que as perspectivas teóricas mais debatidas nos estudos sobre a pacificação e a resolução de conflitos incentivam o fortalecimento dos vínculos comunitários e a participação ativa da população local. De acordo com esses autores, muitas dessas abordagens têm por base as ideias do pedagogo Paulo Freire sobre a educação popular e protagonismo.

Apesar de não se fundamentar nas teorias sobre a pacificação, a ideia de que o esporte exerce um efeito compensatório que dá vazão às tensões do cotidiano, "canalizando" a violência, aparece como interpretação sobre o uso do esporte nesses projetos (GONÇALVES, 2004; MEZZAROBA, 2008; SCHANTZ, 2008; ZALUAR, 2012). Inspirados na obra de Elias e Dunning (1992), esses autores fazem uma leitura otimista sobre o uso paliativo do esporte em virtude do efeito catártico e moderador que ele promove. 0 controle das emoções por meio da excitação em níveis socialmente aceitáveis é considerado o elemento-chave para que os participantes desses projetos exerçam um controle mais rigoroso sobre seu comportamento na sociedade. Em suma, para essa corrente, o esporte tem uma influência "civilizadora" (MEZZAROBA, 2008; SCHANTZ, 2008; ZALUAR, 2012).

Uma segunda alegação parte da universalidade do fenômeno esportivo. A popularidade dos esportes é elencada como um elemento capaz de atrair tanto o público-alvo desses projetos quanto os patrocinadores e apoiadores, constituindo-se numa estratégia barata e eficaz para integrar os participantes (CARDENAS, 2013; DONNELLY et al., 2011).

Ao sintetizar a análise de diferentes autores sobre o tema, Coalter (2007) afirmou que aqueles que adotam uma postura mais cética sobre esse potencial do esporte partem do entendimento de que ele também pode ser um vetor para a agressão, violência e intolerância. A crítica é que essas alegações têm bases especulativas, ingênuas e anedóticas, o que torna difícil uma avaliação mais aprofundada das reivindicações sobre o esporte enquanto 
instrumento para a mudança e a transformação social (SPORT FOR DEVELOPMENT AND PEACE INTERNATIONAL WORKING GROUP, 2007).

Shields e Bredemeier (1996) reconhecem os limites da educação para a paz uma vez que as representações contemporâneas do esporte de alto rendimento estão fortemente associadas à promoção de comportamentos predominantemente egocêntricos, hostis e masculinizantes. Outra crítica é que os grupos aos quais as iniciativas de reconciliação são destinadas, na maioria dos casos, mantêm-se divididos no contexto macrossocial (BAIRNER, 2013).

A literatura problematiza ainda a formação dos responsáveis pelo desenvolvimento das atividades e idealização dos projetos. O primeiro grupo, geralmente composto por profissionais de Educação Física, treinadores esportivos, educadores e voluntários, tem pouco ou nenhum conhecimento específico sobre pacificação e resolução de conflitos. Já o segundo grupo, composto pelos conciliadores, militares e pesquisadores, não necessariamente está familiarizado com as particularidades do esporte ou da pedagogia esportiva, o que limita a análise e a compreensão da relação entre o esporte e a paz (CARDENAS, 2013). A grande questão que se coloca é a necessidade de reconhecer que, por si só, as ações por meio do esporte não geram mudanças sociais significativas; portanto, não devem ser promovidas como uma panaceia para curar problemas sociais que são frutos de processos complexos e multidimensionais (DONNELLY et al., 2011; SCHULENKORF; SUGDEN; BURDSEY, 2014; SUGDEN, 2008).

Os críticos da globalização no esporte ressaltam as ligações desse movimento com o projeto político da Terceira Via ${ }^{2}$, por meio dos discursos em prol das saídas coletivas para o desenvolvimento internacional, formação para a cidadania e interdependência universal. 0 idealismo presente na ideia de que o esporte coloca as semelhanças humanas acima das diferenças culturais é criticado por esses autores. Eles apontam que as relações de poder no campo esportivo são reproduzidas dentro do setor do EDP, no qual as potências mundiais ocidentais são dominantes (DARNELL; HAYHURST, 2012; DONNELLY et al., 2011; JESUS, 2011; JESUS, 2014; SOUZA, 2014). Estes autores destacam o caráter neocolonialista destas intervenções, uma vez que elas são implementadas sem que a população local seja consultada.

Ainda que não seja possível fornecer aqui uma revisão abrangente de todas as raízes epistemológicas para essas interpretações e tipologias, convém considerar aquelas que são mais relevantes para informar e fortalecer o posicionamento cético e o posicionamento favorável ao uso do esporte para a pacificação. A síntese das críticas endereçadas ao setor de EDP alinham-se com os argumentos típicos do realismo de esquerda, conforme apontado por Sugden (2010). Essa vertente da criminologia crítica adota um viés marxista para defender a utilização de estratégias que visam combater os processos que perpetuam a exclusão social, preconizando a justiça sobre a ordem social. Para Jock Young, um dos principais proponentes do realismo de esquerda, a descriminalização do indivíduo e o combate às condicionantes estruturais para a criminalidade são uma demanda basilar (AZEVEDO, 2000). Além disso, a influência da sociologia do esporte na produção do conhecimento sobre os projetos sociais esportivos tem se orientado para uma clara rejeição da leitura essencialista sobre o esporte (COALTER, 2007). 
Em contrapartida, entre os favoráveis identifica-se que, além das narrativas pautadas no "grande mito esportivo" (COAKLEY, 2015), legitimam-se as funções civilizatórias do esporte (ELIAS; DUNNING, 1992). A influência das ideias de Jason Wilson dentro do realismo de direita culminou na forte valorização do behaviorismo e do condicionamento como medidas preventivas para manutenção da ordem e da paz social (AZEVEDO, 2000).

Algumas recomendações são esboçadas nos estudos que investigam este tema. Entre os favoráveis, o papel das instituições na mudança social e cultural em direção à paz é de reforçar a internalização do autocontrole e da conformidade com leis, facilitando o crescimento e a efetividade do controle social informal por meio de iniciativas estruturadas. Todavia, na ausência de modelos próprios de intervenção, essas atividades carecem de um direcionamento claro para a prática (LUGUETTI, 2014).

Entre os céticos, três aspectos são ressaltados para o encaminhamento das iniciativas por meio do esporte. 0 primeiro deles refere-se à sensibilidade cultural. As dinâmicas culturais específicas de cada região e a origem dos conflitos atuam como condicionantes para 0 acolhimento ou rejeição de propostas; logo, elas precisam ser estudadas a priori. As questões ligadas a religião, gênero e etnias precisam ser consideradas, não só por aqueles que lidam diretamente com o desenvolvimento das atividades, como também pelos responsáveis pela gestão (SCHULENKORF; SUGDEN; BURDSEY, 2014; SUGDEN, 2010; ZALUAR, 2012).

Em segundo lugar, é apontada a necessidade de esses projetos permitirem que as comunidades desenvolvam ações próprias. Isso parte do reconhecimento de que o públicoalvo compreende os motivos do rompimento de conflitos e que é capaz de apontar as condições necessárias para a superação desses problemas. Diante disso, as intervenções com o esporte para a pacificação teriam um papel intermediador na construção de laços de confiança, promoção do diálogo e identificação dos interesses comuns (CARDENAS, 2013; GIULIANOTTI, 2011; SILVA; SILVA, 2014; SUGDEN, 2010).

Um terceiro aspecto é em relação à sustentabilidade dos projetos. Em muitos casos, estas iniciativas acontecem por um tempo e, por diversos motivos, desde a falta de recursos até a intensificação dos conflitos, elas se encerram sem que a população local consiga dar prosseguimento às atividades. Alguns autores sugerem que os recursos e as instalações utilizadas sejam compatíveis com a situação local, bem como que líderes locais sejam formados para garantir a participação e a continuidade do projeto de modo independente (CECCHETTO; CORRÊA; FARIAS, 2016; DONNELLY et al., 2011; GIULIANOTTI, 2011).

No que diz respeito ao monitoramento e à avaliação das atividades realizadas no âmbito desses projetos, há um consenso entre ambas as partes de que estes podem gerar subsídios de análise sobre o impacto das intervenções EDP e apontar como os projetos podem ser aprimorados para atuarem de modo mais efetivo e em parceria com o público-alvo (SUGDEN, 2010; VIANNA; LOVISOLO, 2009). Entre os favoráveis, é preponderante o uso de indicadores específicos para a avaliação do impacto dos projetos de pacificação (IOANNOU, $2014)^{3}$ e o desenvolvimento de estudos longitudinais que buscam avaliar o contexto pré e pós

3 O Índice de Coesão e Reconciliação Social (SCORE) é uma ferramenta que tem sido empregada na avaliação de programas que contam com o apoio das agências de desenvolvimento. Ele foi desenvolvido através de uma parceria entre o Programa das Nações Unidas para o Desenvolvimento e o Center for Sustainable Peace and Democratic Development, com financiamento da Ajuda Internacional dos Estados Unidos. O SCORE busca mensurar os níveis de coesão social e reconciliação como dois indicadores da paz. Isso é feito fornecendo pontuações em várias dimensões, para diferentes grupos e também para várias categorias demográficas dentro desses grupos (IOANNOU, 2014). No que se refere ao impacto 
implementação dos programas de pacificação, gerando uma grande quantidade de variáveis passíveis de análises comparativas. Entre os críticos do movimento, existe um intenso debate sobre as metodologias a serem empregadas, havendo uma predileção pelas avaliações de processo às avaliações de impacto. Assim, há um apelo pelo uso de indicadores que informem como as mudanças se efetivaram a partir das ações desses projetos e pela adoção de metodologias alternativas que permitam explorar dimensões pouco acessíveis aos métodos quantitativos (COALTER, 2007; SUGDEN, 2014). Todavia, a literatura carece de exemplos que tenham empregado as recomendações da vertente cética.

\subsection{Esporte e a paz nos contextos das favelas pacificadas}

No ano de 2008, deu-se início a uma política de enfrentamento às facções criminosas que dominavam as favelas da cidade do Rio de Janeiro. Essa nova estratégia era parte do Programa Nacional de Segurança Pública com Cidadania (PRONASCI), aprovado no ano de 2007, mesmo período em que o Rio de Janeiro sediava os Jogos Pan e Parapan-Americanos, com a intenção de se candidatar a sede dos Jogos Olímpicos e Paralímpicos de 2016, e o Brasil foi eleito como sede da Copa do Mundo FIFA 2014. O governo estadual passou então a investir em operações militares com objetivo de retomar o controle destas comunidades que, pode-se dizer que desde os anos de 1980, estavam abandonadas pelo poder público. As ocupações das comunidades pelo Batalhão de Operações Especiais (BOPE) visavam à implementação de Unidades de Polícia Pacificadora (UPP) que administrariam a segurança local (CECCHETTO; CORRÊA; FARIAS, 2016). Além do enfrentamento da violência e prevenção da criminalidade, a ocupação definitiva da favela tinha como objetivo prioritário aproximar as forças policiais da comunidade local. Através do aprofundamento dos vínculos com os moradores, a polícia poderia então estabelecer relações institucionais, especialmente com as associações de moradores (GAWRYSZEWSKI, 2013).

Para dar consistência e materialidade a este objetivo, cria-se em 2010 o programa "UPP Social"4 , com o objetivo de contribuir para a consolidação do processo de pacificação, promover a cidadania local das 30 comunidades ocupadas através do desenvolvimento urbano, social e econômico dessas regiões e efetivar a integração plena dessas áreas ao conjunto da cidade (INSTITUTO PEREIRA PASSOS, 2016). Ainda hoje, por meio da gestão de informações, o programa mapeia os principais problemas dessas comunidades e as potencialidades de cada território "pacificado". Através da gestão institucional, equipes de gestores e assistentes de monitoramento de comunicação, por meio do convênio com o ONU-Habitat, são responsáveis por identificar as demandas, elaborar diagnósticos das comunidades pacificadas, viabilizar estratégias para estreitar os laços com os moradores e desenvolver atividades socioeducativas com jovens e crianças.

Em algumas favelas, as vilas olímpicas e os projetos liderados por moradores que ensinavam voluntariamente esportes variados e atividades culturais para crianças e jovens já existiam há muitos anos (CECCHETTO; CORRÊA; FARIAS, 2016; TEIXEIRA, 2015; ZALUAR, 2012). Com o surgimento do programa "Rio Mais Social", deu-se início às tentativas de aproximação entre a polícia e a comunidade por meio da oferta de aulas de esporte e de

4 A partir de 2011, o Instituto Municipal de Urbanismo Pereira Passos, órgão vinculado à prefeitura do Rio de Janeiro, em parceria com o ONU-Habitat (Programa das Nações Unidas para Assentamentos Humanos) passa a coordenar o programa sob o nome "Rio Mais Social". O nome atual será utilizado indistintamente ao longo do texto em referência tanto às ações desenvolvidas pelo então chamado "UPP Social" quanto pelo "Rio Mais Social". 
música pelos soldados. Foi neste contexto que surgiu a figura do policial social, responsável pelo exercício do combate à criminalidade local, ao mesmo tempo em que exerceria ações preventivas por meio de atividades de cunho socioeducativo (TEIXEIRA, 2015). Isso implicou na criação de estratégias de persuasão não só da comunidade sobre a diferença entre esse policial e o soldado do BOPE, por exemplo, mas em se criar um novo habitus do profissional que atua nas comunidades pacificadas (GAWRYSZEWSKI, 2013; TEIXEIRA, 2015).

Existem duas questões que emergem frente a esta mudança de papéis. A primeira diz respeito ao aumento no clima de desconfiança mútua entre os policiais e a comunidade, especialmente por parte dos moradores mais jovens (ZALUAR, 2012). A população local teme a violência e a delação por parte dos militares, que, por sua vez, identificam especialmente os jovens como "inimigos em potencial". Teixeira (2015) analisa o papel do policial social nas UPP e problematiza a ambivalência de sua condição marginal, uma vez que é tênue a linha que separa a atuação ostensiva contra o crime e a violência e as atividades de cunho preventivo no âmbito dos projetos esportivos.

$\mathrm{Na}$ tentativa de diminuir a reatividade dos moradores das comunidades e permitir a construção de uma identidade profissional diferenciada para esses policiais sociais, policiais recém-ingressados na corporação, e que, portanto, não teriam realizado atividades de combate em áreas de favela, foram designados para atuar nas unidades. Apesar dessa tentativa, a população protestou contra a forma como os policiais atuavam nos projetos sociais destinados aos jovens, uma vez que se replicava o modelo militarizado, hierárquico e disciplinar de ensino do esporte (CECCHETTO; CORRÊA; FARIAS, 2016; GAWRYSZEWSKI, 2013; TEIXEIRA, 2015; ZALUAR, 2012).

Uma segunda questão está ligada a um olhar estigmatizante sobre a população jovem que reside nas favelas. A pobreza resultante da desigualdade social é o fator que fundamenta a ideia de que esse grupo está mais propenso à delinquência e ao uso de drogas, devendo, portanto, participar desses projetos sociais para vivenciar a socialização positiva. Zaluar (2012) ressalta que o fator preponderante no envolvimento de alguns desses jovens com a criminalidade não é a pobreza, mas a exclusão, termo que se refere a diversos processos simultâneos, desde o afastamento da escola até a diluição dos laços vicinais dentro das comunidades. Essa simplificação dos processos de exclusão social por parte dos proponentes desses programas implica a escolha de estratégias que intensificam certos determinantes.

A substituição dos professores e voluntários moradores das comunidades, e, portanto, conhecedores das regras locais, por policiais sociais para ensinarem os esportes fragiliza ainda mais a capacidade organizativa dos moradores (ZALUAR, 2012). A inserção de militares como instrutores desses projetos esportivos de caráter social tende a intensificar o uso das formas sutis de intervenção contra a criminalidade que acaba por sobressair à tarefa preventiva para qual também estão designados. Assim, há uma transitoriedade entre os papéis que a comunidade e os policiais sociais passam a assumir nesta relação: "[...] policiais, professores, agentes sociais, alunos, suspeitos, potenciais inimigos, informantes" (TEIXEIRA, 2015, p. 94).

Nessas comunidades, onde os campeonatos esportivos, concursos e desfiles de carnaval envolvendo bairros e segmentos populacionais rivais eram importantes elementos da vida social, a inserção dos militares como instrutores a partir da nova política de segurança enfraquece a participação e o protagonismo popular em nome de uma política de intervenção que mistura prevenção e combate (ZALUAR, 2012). Cria-se uma nova categoria de intervenção 
militar que nada mais é do que um novo aspecto da "guerra molecular" (ZALUAR, 2012, p. 349) na qual o combate ao comércio de drogas no varejo é intensificado em detrimento do combate às redes internacionais do narcotráfico e do crime organizado, por exemplo. Para a autora, as medidas de prevenção que buscam impedir o avanço da criminalidade nessas comunidades precisam focalizar na reconstrução dos laços vicinais em vez de promover iniciativas de infiltração que fragilizam as estruturas de controle social informal entre os vizinhos. Assim, é cada vez mais necessário que se ofereça apoio para o trabalho realizado pelas lideranças locais, que já desenvolvem atividades esportivas e culturais, para que essas ações sejam potencializadas e se espalhem pelas outras comunidades.

Entretanto, como Zaluar (2012) reconhece, existem sérias limitações na utilização dos conceitos de coesão social e capital social, já que existe uma tendência em se partir da realidade dos subúrbios americanos, onde há relativa homogeneidade étnica e religiosa. Notadamente, o contexto das comunidades brasileiras, em que as diferentes culturas regionais e convicções se encontram, impõe desafios semelhantes àqueles que se apresentam nas iniciativas de reconciliação de comunidades divididas. Em Israel, na Irlanda do Norte e no continente africano, as experiências caminharam em direção à promoção e/ou ao fortalecimento das iniciativas locais de promoção do esporte para crianças e adolescentes, buscando estimular a confiança mútua, a sociabilidade e a possibilidade de ação conjunta entre as comunidades (LINDSEY; GRATTAN, 2012; SUGDEN, 2010; SUGDEN; HAASNER, 2009). É possível que um apoio nesta direção contribua para o aumento do envolvimento popular e da garantia da sustentabilidade destes projetos.

A atuação de diferentes setores na nova política de segurança é destaque no contexto da pacificação através do esporte. Por meio de um setor de mobilização e parceria, o programa Rio Mais Social tem buscado fomentar ações em parceria com a sociedade civil e a iniciativa privada nas regiões com UPP. O objetivo principal é identificar e desenvolver projetos nas áreas da cultura, esporte, empreendedorismo, saúde, meio ambiente e educação que venham a produzir resultados para o processo de integração da cidade (INSTITUTO PEREIRA PASSOS, 2016).

Desde 0 ano de 2010, diferentes organizações investiram recursos para a construção das sedes das UPP, contratação de pessoal, oferta de serviços e financiamento de projetos. O investimento total e a duração dessas parcerias são diversos, mas os críticos das ações do setor de mobilização e parceria do Rio Mais Social não restringem a desconfiança aos possíveis interesses do setor privado com essas iniciativas. 0 crescente interesse dos setores de responsabilidade social das empresas e de particulares em investir no esporte e em inciativas de cunho social tornam o contexto dos projetos sociais esportivos nas áreas de pacificação bastante atrativo. Para Gawryszewski (2013), o programa Rio Mais Social atrai desde as grandes empresas até as celebridades do esporte que vislumbram a possibilidade de se beneficiarem por meio do marketing social. De fato, a associação simplista entre a oferta de projetos sociais esportivos, a prevenção da violência e a promoção da paz também é um recurso utilizado pelos setores público e privado na busca por visibilidade e alinhamento com as propostas das agências internacionais de desenvolvimento (JESUS, 2011; NOZAKI; PENNA, 2007; REIS; SOUSA-MAST; VIEIRA, 2013; SOUZA, 2014).

$\mathrm{Na}$ leitura de Hecktheuer (2012), o panorama de crescimento dessas iniciativas aponta para uma nova estratégia de solução de problemas sociais, levando-o a adotar o termo "sociedade de projetos". Essas "novas" ações ainda levantam muitas questões em relação à 
efetividade e ao impacto que produzem. A principal questão repousa na dificuldade em reunir indicativos sobre o quanto (e como) essas iniciativas têm se concretizado frente aos objetivos traçados por parte dos idealizadores.

A avaliação de impacto, ou seja, o levantamento das mudanças efetivadas na vida das pessoas em decorrência da ação destes projetos sociais, traz indicativos que extrapolam os resultados alcançados pelo programa (dados quantitativos sobre a sua abrangência, por exemplo). No entanto, este tipo de avaliação está ligado ao uso de procedimentos metodológicos pautados em uma tradição positivista, tais como os modelos experimentais ou quase-experimentais (pré e pós teste) e ao controle das variáveis intervenientes. 0 ceticismo, principalmente por parte dos pesquisadores do campo das ciências sociais, é sobre a possibilidade de isolar a variável esporte e, ainda, sobre a "fidedignidade sociológica" em que tal tentativa resultaria (COALTER, 2007; JANSEENS, 2004).

A estrutura gerencial do programa Rio Mais Social prevê avaliações de processo, na qual a eficiência das operações do programa é monitorada (INSTITUTO PEREIRA PASSOS, 2016); entretanto, muito mais do que detectar processos que dão mais ou menos certo dentro do programa, existe a necessidade de se problematizar até que ponto o uso do esporte para a meta de integração plena das áreas "pacificadas" ao conjunto da cidade do Rio de Janeiro se efetiva ao longo desse processo.

\section{CONSIDERAÇÕES FINAIS}

O uso do esporte para a reconciliação, a promoção da cultura de paz e a prevenção da violência tem sido questionado, apesar da difusão de ações que veem no esporte uma linguagem universal, capaz de difundir atitudes socialmente desejáveis e incitar um efeito catártico moderador em seus participantes. As análises acerca do esporte para a paz na literatura apontam para alguns paralelos sobre o uso do esporte nas favelas pacificadas do Rio de Janeiro.

A proposta pautada na retomada da ordem local e na verticalização da orientação didático-pedagógica a partir da intervenção dos policiais indica um alinhamento com a vertente favorável. No contexto de pacificação de algumas favelas do Rio de Janeiro, a militarização do espaço das comunidades e o uso do esporte como estratégia de aproximação entre os policiais militares e a população local representa, de um lado, a retomada do território pelo poder público, mas, por outro lado, levanta o risco de enfraquecimento do protagonismo dos moradores nas iniciativas de esporte, lazer e cultura.

A presença do policial social como mediador das atividades esportivas é, em tese, a possibilidade de efetivar ações preventivas, porém, ainda se faz necessária uma ampliação no debate público sobre o papel dos militares nesses espaços. A reprodução de práticas hierárquicas em nome da ordem pública na gestão do Programa Rio Mais Social traz dúvidas sobre a consideração das questões ligadas à sensibilidade cultural e os processos de exclusão social por parte de seus idealizadores, bem como acerca da sustentabilidade e o protagonismo popular nestes projetos esportivos a longo prazo.

No que se refere à oferta dos projetos de pacificação, o apelo da vertente cética é em prol da adoção de modelos didáticos sustentados pelos pressupostos da pedagogia crítica. 
Nessa perspectiva, existe o potencial de se elencar subsídios para a tomada de decisão informada na estruturação do ambiente pedagógico dessas atividades, rompendo-se com a leitura essencialista e eminentemente positiva sobre o uso do esporte (COAKLEY, 2015; COALTER, 2007; LUGUETTI, 2014; SUGDEN, 2010).

Nosso empenho aqui não foi em nos colocarmos em prol da defesa de um dos posicionamentos. Mais do que isso, entendemos que existe a necessidade de uma ponderação sobre as nuances que permeiam as iniciativas por meio do esporte para consolidação da pacificação. A ênfase que é dada pela mídia, pelo Estado, pelas empresas e pelas próprias agências internacionais de desenvolvimento tendem a suprimir a complexidade dos diferentes processos sociais que criam e mantêm determinadas realidades.

Similarmente, na polarização dos posicionamentos sobre as formas de se avaliar 0 impacto e a legitimidade dessas iniciativas, abre-se o campo para as disputas paradigmáticas e as múltiplas tentativas de negação das perspectivas divergentes, a fim de promover um determinado conjunto de princípios válidos para um percurso avaliativo. A vertente crítica passou a dominar diferentes espaços no meio acadêmico, apontando as falhas metodológicas e a ambição dos métodos experimentais. No entanto, num contexto de disputas como este, a notabilização de um ou outro posicionamento representa muito mais o silenciamento das divergências epistemológicas do que a sua superação. A consequência mais imediata tem sido o distanciamento das demandas que surgem da intervenção, prejudicando a geração e 0 uso de novos conhecimentos no cotidiano dos projetos esportivos já implementados (CRONIN, 2011).

Isto posto, muito mais do que empenhar uma crítica sobre a falta de avaliação e monitoramento ou ainda sobre os limites dos projetos de pacificação por meio do esporte, verifica-se a necessidade de se investigar o espaço social no qual essas propostas se constroem e os mecanismos e estratégias empenhados para a manutenção dos discursos e das práticas em prol da paz.

\section{REFERÊNCIAS}

AISENBERG, Eugene et al. Defining violence. In: HERRENKOHL, Todd et al. (Ed.). Violence in Context: Current Evidence on Risk, Protection, and Prevention. New York: Oxford, 2011. p. 1327.

AZEVEDO, Rodrigo Ghiringhelli de. Controle penal em tempo de mudança: Brasil e Argentina. Porto Alegre: Consejo Latinoamericano de Ciencias Sociales, 2000.

BAIRNER, Alan. Sport, the Northern Ireland peace process, and the politics of identity. Journal of Aggression, Conflict and Peace Research, v. 5, n. 4, p. 220-229, 2013.

BLAKEMORE, Ken; GRIGGS, Edwin. Social policy: an introduction. 3. ed. Buckingham: Open University, 2007.

CARDENAS, Alexander. Peace Building Through Sport? An Introduction to Sport for

Development and Peace. Journal of Conflitology, v. 4, n. 1, p. 24-33, 2013. 
CECCHETTO, Fátima; CORRÊA, Juliana; FARIAS, Patrícia. Quando o projeto era moda: Projetos sociais, juventudes e a política de "pacificação" no Rio de Janeiro. BRASILIANAJournal for Brazilian Studies, v. 4, n. 2, p. 483-512, 2016.

CERQUEIRA, Daniel Ricardo de Castro. Causas e conseqüências do crime no Brasil. 2010. 168 f. Tese (Doutorado) - Curso de Economia, Departamento de Economia, Pontíficia Universidade Católica do Rio de Janeiro, Rio de Janeiro, 2010.

COAKLEY, Jay. Assessing the sociology of sport: On cultural sensibilities and the great sport myth. International Review for the Sociology of Sport, v. 50, n. 4-5, p. 402-406, 2015.

COALTER, Fred. A Wider Social Role for Sport: Who's Keeping the Score? London: Routledge, 2007.

COMITEE OLÍMPICO INTERNACIONAL. International day of sport for development and peace. 2015a. Disponível em: <https://www.olympic.org/idsdp>. Acesso em: 26 maio 2016.

COMITÊ OLÍMPICO INTERNACIONAL. UN general assembly includes sport in post-2015 sustainable development goals. IOC News, 25 set. 2015b. Disponível em: <https://www.olympic. org/news/un-general-assembly-includes-sport-in-post-2015-sustainable-development-goals $>$. Acesso em: 28 maio 2016.

CRONIN, Órla. Comic Relief Review: Mapping the Research on the Impact of Sport and Development Intervention. Manchester: Orla Cronin Research, 2011.

DARNELL, Simon; HAYHURST, Lyndsay. Hegemony, postcolonialism and sport-fordevelopment: a response to Lindsey and Grattan. International Journal of Sport Policy and Politics, v. 4, n. 1, p. 111-124, 2012.

DONNELLY, Peter et al. Sport for Development and Peace: a public sociology perspective. Third World Quarterly, v. 32, n. 3, p. 589-601, 2011.

ELIAS, Norbert; DUNNING, Eric. A Busca da Excitação. Lisboa: Difel, 1992.

GALTUNG, Johan. Peace by Peaceful Means: peace and conflict, development and civilization. London: SAGE, 1996.

GAWRYSZEWSKI, Bruno. O esporte nas favelas ocupadas pela polícia e a produção discursiva da imprensa. Motrivivência, n. 40, p. 106-120, 2013.

GIDDENS, Anthony (org.). 0 debate global sobre a Terceira Via. São Paulo: Editora UNESP, 2007.

GIULIANOTTI, Richard. O setor de esporte para o desenvolvimento e a paz: um modelo sociológico de agências pacificadoras. Pensar a Prática, v. 15, n. 3, p. 553-574, 2012.

GIULIANOTTI, Richard. Sport, peacemaking and conflict resolution: a contextual analysis and modelling of the sport, development and peace sector. Ethnic and Racial Studies, v. 34, n. 2, p. 207-228, 2011.

GIULIANOTTI, Richard; ARMSTRONG, Gary. Sport, the Military and Peacemaking: history and possibilities. Third World Quarterly, v. 32, n. 3, p. 379-394, 2011.

GONÇALVES, Maria Alice Rezende. Educação e Esporte: antídotos contra a violência. Revista Rio de Janeiro, n. 12, p. 1-20, 2004. 
GÜLDENPFENNIG, Sven. Sport in the peace movement: a challenge for the sport science. International Review for the Sociology of Sport, v. 20, n. 3, p. 203-213, 1985.

HECKTHEUER, Luiz Felipe Alcântara. Esporte e segurança em uma "sociedade de projetos". Motrivivência, n. 38, p. 98-107, 2012.

IOANNOU, Maria. Center For Sustainable Peace And Democratic Development. An introduction to the Social Cohesion and Reconciliation Index (SCORE). 2014. Disponível em: <https:// www.google.com.br/url?sa=t\&rct=j\&q=\&esrc=s\&source=web\&cd=1\&cad=rja\&uact=8\&ved=0ahU KEwjq2-y8x8LUAhVIPz4KHV7LAqUQFggtMAA\&url=http://scoreforpeace.org/app/webroot/files/ general/files/Introduction\%20to\%20SCORE\%20Final\%20share.pdf\&usg=AFQjCNGZdwFuWzfk YrKe6TZvWiylLJbMg\&sig2=ma4DxYxLrvhm3OKt6f4c2g>. Acesso em: 11 jun. 2017.

INSTITUTO PEREIRA PASSOS. Rio Mais Social. Disponível em: <http://www.riomaissocial. org/>. Acesso em: 25 jun. 2016.

JANSEENS, Jan. Educating through sport: an overview of good practices in Europe. Nieuwegein: Arko Sports Media, 2004.

JESUS, Diego Santos Vieira de. Triunfo, desgraça e outros impostores: um ensaio sobre hierarquia e exclusão no esporte e nas relações internacionais. Revista Brasileira de Educação Física e Esporte, v. 25, n. 3, p. 417-430, 2011.

JESUS, Diego Santos Vieira de. Juntos num só ritmo? Diplomacia e esporte internacional. Recorde: Revista de História do Esporte, v. 7, n. 2, p. 1-37, 2014.

KIDD, Bruce. A new social movement: sport for development and peace. Sport in Society, v. 11 , n. 4, p. 370-380, 2008.

KRAVCHYCHYN, Claudio; OLIVEIRA, Amauri Aparecido Bássoli de. Projetos e programas sociais esportivos no Brasil: uma revisão sistemática. Movimento, v. 21, n. 4, p. 1051-1065, 2015.

LINDSEY, lain; GRATTAN, Alan. An 'international movement'? Decentring sport-for-development within Zambian communities. International Journal of Sport Policy and Politics, v. 4, n. 1, p. 91-110, 2012.

LUGUETTI, Carla Nascimento. Movendo-se do que é para o que poderia ser: desenvolvendo um protótipo de modelo pedagógico do esporte para meninos residentes em áreas de vulnerabilidade social no Brasil. 2014. 191 f. Tese (Doutorado) - Curso de Pedagogia do Movimento Humano, Escola de Educação Física e Esporte, Universidade de São Paulo, São Paulo, 2014.

MANGAN, James. Athleticism in the Victorian and Edwardian Public School: the Emergence and Consolidation of an Educational ideology. London: Frank Cass, 2000.

MEZZAROBA, Cristiano. O esporte nos projetos sociais: reflexões através das contribuições de Norbert Elias. Lecturas Educación Física y Deportes, v. 13, p. 124-129, 2008.

NOZAKI, Takeuchi Hajime; PENNA, Adriana Machado. O novo papel do esporte no contexto da ofensiva imperialista recolonizadora. Outubro Revista, n. 16, p. 201-217, 2007.

NYGÅRD, Håvard Mokleiv; GATES, Scott. Soft power at home and abroad: Sport diplomacy, politics and peace-building. International Area Studies Review, v. 16, n. 3, p. 235-243, 2013. 
ORGANIZAÇÃO DAS NAÇÕES UNIDAS. Esporte para o Desenvolvimento e a Paz: em Direção à Realização das Metas de Desenvolvimento do Milênio. 2003. Disponível em: <http://www.esporte. gov.br/arquivos/publicacoes/esporteParaDesenvolvimentoPaz.pdf>. Acesso em: 7 maio 2016.

PROGRAMA DAS NAÇÕES UNIDAS PARA O DESENVOLVIMENTO. Transformando o nosso mundo: a agenda 2030 para o desenvolvimento sustentável. 2016. Disponível em: $<$ <ttp://www.pnud.org.br/Docs/Agenda2030completo_PtBR.pdf>. Acesso em: 25 jul. 2016.

REIS, Ariane; SOUSA-MAST, Fabiana; VIEIRA, Marcelo Carvalho. Public policies and sports in marginalised communities: the case of Cidade de Deus, Rio de Janeiro, Brazil. World Leisure Journal, v. 55, n. 3, p. 229-251, 2013.

SCHANTZ, Otto. Pierre de Coubertin's "Civilizing Mission". In: BARNEY, Robert K. et al. (eds.). Pathways: critiques and discourse in Olympic Research. London: International Centre for Olympic Studies, 2008. p. 53-62.

SCHULENKORF, Nico; SUGDEN, John.; BURDSEY, Daniel. Sport for development and peace as contested terrain: place, community, ownership. International Journal of Sport Policy and Politics, v. 6, n. 3, p. 371-387, 2014.

SHIELDS, David Lyle Light; BREDEMEIER, Brenda Jo Light. Sport, Militarism, and Peace. Peace and Conflict: Journal of Peace Psychology, v. 4, n. 2, p. 369-383, 2016.

SILVA, Orestes Manoel da; SILVA, Carlos Alberto Figueiredo da. Desenho da rede de um projeto esportivo social: atores, representações e significados. Revista Brasileira de Educação Física e Esporte, v. 28, n. 3, p. 415-428, 2014.

SOUZA, Carlos Eduardo de. Estado cosmopolita, organismos internacionais e a terceira via: 0 esporte enquanto política social. Motrivivência, v. 26, n. 4, p. 41-54, 2014.

SPAAIJ, Ramón. Sport as a vehicle for social mobility and regulation of disadvantaged urban youth: Lessons from Rotterdam. International Review for the Sociology of Sport, v. 44, p. 247-264, 2009.

SPAAIJ, Ramón. Sport and social policy. In: MAGUIRE, Joseph. Social sciences in sport. Leeds: Human Kinetics, 2014. p. 277-304.

SPORT FOR DEVELOPMENT AND PEACE INTERNATIONAL WORKING GROUP. Literature reviews on sport for development and peace. 2007. Disponível em:<http://www.righttoplay. com/moreinfo/aboutus/Documents/LiteratureReviewsSDP.pdf>. Acesso em: 21 jun. 2016.

SPORT FOR DEVELOPMENT AND PEACE INTERNATIONAL WORKING GROUP. Harnessing the power of sport for development and peace: recommendations to governments. 2008. Disponível em: <http:/www.un.org/wcm/webdav/site/sport/shared/sport/pdfs/ SDP IWG/Final SDP IWG Report.pdf>. Acesso em: 14 jun. 2016.

SUGDEN, John. Anyone for Football for Peace? The challenges of using sport in the service of co-existence in Israel. Soccer \& Society, v. 9, n. 3, p. 405-415, 2008.

SUGDEN, John. Critical left-realism and sport interventions in divided societies. International Review for the Sociology of Sport, v. 45, n. 3, p. 258-272, 2010.

SUGDEN, John. The Ripple Effect: Critical Pragmatism, Conflict Resolution and Peace Building through Sport in Deeply Divided Societies. In: SCHULENKORF, Nico; ADAIR, Daryl. Global sport-for-development: Critical perspectives. Basingstoke: Palgrave Macmillan, 2014. p. 79-98. 
SUGDEN, John; HAASNER, Adrian. Sport Intervention in Divided Societies. 2009. Disponível em: <http://www.football4peace.eu/Downloads/Publications/sugdenhaasner2009.pdf>. Acesso em: $1^{\text {o }}$ abr. 2016.

TEIXEIRA, Cesar Pinheiro. O 'policial social': Algumas observações sobre o engajamento de policiais militares em projetos sociais no contexto de favelas ocupadas por UPPs. Dilemas, v. 8, n. 1, p.77-96, 2015.

VIANNA, José Antônio; LOVISOLO, Hugo Rodolfo. Projetos de inclusão social através do esporte: notas sobre a avaliação. Movimento, v. 15, n. 3, p. 145-162, 2009.

WEBB, Andrew; RICHELIEU, André. Sport for Development and Peace in Action: Building Facts for Funding. Journal of Sport \& Social Issues, v.40, n.5, p. 1-25, 2016.

WORLD HEALTH ORGANIZATION. Global consultation on violence and health: Violence - a public health priority. Geneva: World Health Organization, 1996.

ZALUAR, Alba. Juventude violenta: processos, retrocessos e novos percursos. Dados: Revista de Ciências Sociais, v. 55, n. 2, p. 327-365, 2012.

ZDUN, Steffen. Difficulties Measuring and Controlling Homicide in Rio de Janeiro. International Journal of Conflict and Violence, v. 1, n. 5, p.188-199, 2011. 